\title{
The release of persistent organic pollutants from a closed system dicofol production process
}

\author{
Sumei Li ${ }^{a}$, Yajing Tian ${ }^{\mathrm{b}}$, Qiong Ding ${ }^{\mathrm{b}}$, Wenbin Liu ${ }^{\mathrm{a}, *}$ \\ a State Key Lab of Environmental Chemistry and Ecotoxicology, Research Center for Eco-Environmental Sciences, Chinese Academy of Sciences, No. 18, Shuangqing Road, \\ Haidian District, Beijing 100085, China \\ ${ }^{\mathrm{b}}$ Foreign Economic Cooperation Office, Ministry of Environmental Protection, No. 5, Houyingfang Hutong, Xicheng District, Beijing 100035, China
}

\section{H I G H L I G H T S}

- PCDD/Fs and $\Sigma$ DDTs in dicofol production process were analyzed.

- The inhalation of $\Sigma$ DDTs in the workplace was evaluated.

- The emissions of $\Sigma$ DDTs and PCDD/Fs in dicofol were calculated.

- The formation pathway of PCDD/Fs was discussed.

\section{A R T I C L E I N F O}

\section{Article history:}

Received 28 June 2013

Received in revised form 3 September 2013

Accepted 21 September 2013

Available online 22 October 2013

\section{Keywords:}

POPs

DDTs

PCDD/Fs

Waste water

Waste acid

\begin{abstract}
A B S T R A C T
High concentrations of polychlorinated dibenzo-p-dioxins and dibenzofurans (PCDD/Fs) have been found to be produced in chemical processes in which chlorine is a raw material. Samples of workshop air, waste water, waste acid, and the dicofol product were collected from a pesticide factory in China that uses a closed-system dicofol production process, and were analyzed for PCDD/Fs and $\Sigma$ DDTs. The $\Sigma$ DDTs concentrations were $1.88-17.53 \mu \mathrm{g} \mathrm{m}^{-3}$ in the workshop air samples, $4.85-456 \mu \mathrm{g} \mathrm{kg}^{-1}$ in the waste water and waste acid samples, and $4.74 \mathrm{~g} \mathrm{~kg}^{-1}$ in the dicofol product. The total estimated daily intakes of $\Sigma$ DDTs for workers by inhalation in the workplace were in the range of $0.38-3.51 \mu \mathrm{g} \mathrm{kg}^{-1} \mathrm{bw} \mathrm{d}^{-1}$ for moderate activities. The annual amounts of $\Sigma$ DDTs and $p, p^{\prime}$-DDT directly released to the environment via the use of dicofol were $9480 \mathrm{~kg}$ and $1080 \mathrm{~kg}$, respectively. The PCDD/F toxicity equivalent values (I-TEQs) in the waste water and waste acid samples ranged from 1.5 to $122 \mathrm{pg} \mathrm{I}$-TEQ kg $^{-1}$ and $86.3 \mathrm{ng}$ I-TEQ $\mathrm{kg}^{-1}$ in the dicofol sample. The annual amount of PCDD/Fs released to the environment was $0.17 \mathrm{~g}$ I-TEQ. From the PCDD/F distribution patterns, it is suggested that the major pathway for PCDD/ $\mathrm{F}$ formation involves precursor synthesis during the production of dicofol in the closed-system process.
\end{abstract}

(c) 2013 Elsevier Ltd. All rights reserved.

\section{Introduction}

Polychlorinated dibenzo-p-dioxins and dibenzofurans (PCDD/Fs) and 1,1,1-trichloro-2,2-bis ( $p$-chlorophenyl) ethane (DDT) are among the persistent organic pollutants (POPs) targeted for international source reduction by the Stockholm Convention. Exposure to these POPs is of great concern because of their toxicities, including the induction of hormone-dependent cancers and reproductive effects in humans and wildlife. PCDD/Fs and DDTs are only degraded with difficulty but bioaccumulated and biomagnified strongly, and are considered to be harmful to humans and the environment.

The direct use of DDTs has been restricted, within narrow constraints, since 2002, and most DDTs have been used in the synthesis of dicofol (2,2,2-trichloro-1,1-bis (4-chlorophenyl) ethanol)

\footnotetext{
* Corresponding author. Tel.: +86 10 62849356; fax: +86 1062923563 .

E-mail address: liuwb@rcees.ac.cn (W. Liu).
}

since that time. Records show that the average annual DDTs production rate in China was about 6000 t from 1988 to 2002, and nearly $80 \%$ of that was used to produce dicofol (Qiu et al., 2005). Dicofol is an organochlorine acaricide that is effective against a broad spectrum of pests with a high activity, but has a low toxicity to the natural enemies of the pests and crops, which is currently used widely to prevent mite damage to cotton, fruit, sugarcane, hawthorn, pawpaw, and flowers. Dicofol is produced from $\mathrm{C}_{6} \mathrm{H}_{5} \mathrm{Cl}$ and $\mathrm{CCl}_{3} \mathrm{CHO}$, with DDTs being an intermediate. Dicofol may, therefore, contain high concentrations of DDT-related compounds as impurities, and has become an important source of DDTs (Zhang et al., 2002; Li et al., 2006; de la Cal et al., 2008; Chen et al., 2009). China has had one of the highest levels of DDTs production and consumption in the world (Hui et al., 2008). Serious DDTs pollution has been reported in cotton fields in northern Jiangsu province, China, and the use of dicofol accounted for nearly $80 \%$ of the DDTs found (Yang et al., 2008). 
Besides, PCDD/Fs can be produced as impurities in several chemical production processes and from the use of elemental chlorine in the pulp and paper industry (UNEP, 2005). The production of polychlorophenols, polychlorobenzenes, chloranil, and organochlorine pesticides are important sources of PCDD/Fs in China (Liu et al., 2004; Zheng et al., 2008; Liu et al., 2012; Liu et al., 2013). Chlorine is a key ingredient in the production of dicofol, so dicofol production may lead to the formation of PCDD/Fs. However, no data are available on PCDD/Fs formation during dicofol production.

Producing dicofol in non-closed systems was restricted in China in 2009, in order to control DDT releases during dicofol production, and only closed systems are now permitted to be used. Dicofol will be produced in closed systems for several years more in China, so it is important to study DDT and PCDD/F contaminations in the dicofol product. This will enable the environmental risks associated with the production and use of dicofol to be estimated and allow human health and the environment to be protected more effectively.

\section{Experimental section}

\subsection{Sampling}

This study was performed at Sinochem International Corporation, which is the only dicofol-producing enterprise in China, and has an annual dicofol output of around $2000 \mathrm{t}$. Fig. 1 illustrates the dicofol production process.

Dicofol is produced from $\mathrm{CCl}_{3} \mathrm{CHO}$ and $\mathrm{C}_{6} \mathrm{H}_{5} \mathrm{Cl}$, through condensation, alkalization, chlorination, and hydrolyzation processes. First, the condensation reaction of $\mathrm{CCl}_{3} \mathrm{CHO}$ and $\mathrm{C}_{6} \mathrm{H}_{5} \mathrm{Cl}$ in the presence of sulfuric acid yields DDT. Dichlorodiphenyldichloroethylene (DDE) is produced from the DDT in the alkalization process, then which is transferred into a chlorination kettle and mixed with chlorine to produce chlorine-DDT (Cl-DDT, 1,1-bis(p-chlorophenyl)-1,2,2,2-tetrachloroethane). Finally, Cl-DDT is put into a hydrolyzation kettle and reacted with $\mathrm{H}_{2} \mathrm{O}$ to produce dicofol. All of the facilities used in this system are in a controlled workshop and only DDTs are present in the reaction kettle, so that the requirements of the Stockholm Convention are fulfilled.

To allow the potential POPs release from the dicofol production process to be assessed, samples of waste acid, waste water, and the dicofol product were collected for analysis. Two parallel air samples were collected at each of seven sampling sites in the dicofol workshops to evaluate the unintentional release of DDTs. Air samples were collected by an ordinary air sampler (DQ-1A, Jiangfen Instrument $\mathrm{Co}$., China), equipped with fiberglass membrane. The sampling rate was $1 \mathrm{~L} \mathrm{~min}^{-1}$ and the sampling time lasted for $60 \mathrm{~min}$. The sampling information is shown in Table 1.

\subsection{DDTs and $P C D D / F$ analysis}

$\Sigma$ DDTs (including $p, p^{\prime}$-DDE, $o, p^{\prime}$-DDT, $p, p^{\prime}$-DDT, $p, p^{\prime}$-DDD and Cl-DDT) were analyzed following Chinese national standard methods. Each sample was dissolved in hexane and purified by mixing it with $1 / 10$ of its volume of $\mathrm{H}_{2} \mathrm{SO}_{4}$. The resulting solution was concentrated and analyzed using a GC/MS (Agilent 6890/ 5973, Agilent Technologies, USA) equipped with a HP-5 MS capillary column $(30 \mathrm{~m} \times 0.32 \mathrm{~mm}$ i.d. $\times 0.25 \mu \mathrm{m})$. The data were acquired in SIM mode by tracing the two most abundant ions of the molecular ion clusters.

PCDD/Fs were analyzed using a method based on the U.S. Environmental Protection Agency (EPA) method 1613 (Liu et al., 2012). Briefly, ${ }^{13}$ C-labeled PCDD/F standards (1 ng each; Wellington Laboratories, Guelph, Canada) were added to each sample, then $20 \mathrm{~L}$ of waste water or $2 \mathrm{~L}$ of waste acid were extracted with $200 \mathrm{~mL}$ hexane, and $2 \mathrm{~g}$ of dicofol product was dissolved in $100 \mathrm{~mL}$ hexane. The extracts were treated with sulfuric acid (98\%), then the extracts were eluted through a multilayer silica gel column and an alumina column to clean them further. ${ }^{13} \mathrm{C}$-labeled injection standards ( $1 \mathrm{ng}$ ) were then added to each sample before they were analyzed using a HRGC (Agilent 6890, Agilent Technologies, USA) coupled with a HRMS (Waters Autospec Ultima, Waters, USA). A DB-5 MS fused-silica column $(60 \mathrm{~m} \times 0.25 \mathrm{~mm}$ i.d. $\times 0.25 \mu \mathrm{m})$ was used for the separation of congeners. The mass spectrometer was operated in selected ion monitoring mode at a resolution of $\geqslant 10,000$. Field and laboratory blanks were incorporated into the analytical procedure. The recoveries of the $17{ }^{13} \mathrm{C}$-labeled 2,3,7,8PCDD/F congeners added before extraction were between 42.6 and $117.6 \%$, which satisfied the requirements of US EPA Method 1613.

\section{Results and discussion}

\subsection{DDTs emissions}

A certain amount of $\Sigma$ DDTs might be released into the workshop air because of deficiencies in the dicofol production technique or operational problems. The $\Sigma$ DDTs concentrations found in the workshop air samples are shown in Fig. 2.

The air samples were collected from the seven sites in the workshops to assess the EDDTs exposure risk to the workers. The samples contained $\Sigma$ DDTs that had clearly been emitted from the dicofol production process. The concentrations of $\Sigma$ DDTs were in the range of $1.88-17.53 \mu \mathrm{g} \mathrm{m}^{-3}$. In particular, the highest sum of the $\Sigma$ DDT concentrations we found was $17.53 \pm 6.31 \mu \mathrm{g} \mathrm{m}^{-3}$, inside the dicofol product packaging workshop (sample "Air 7"), which might lead to increased risks from workers being exposed to $\Sigma$ DDTs.

Inhalation exposure to $\Sigma$ DDTs in the workplace was roughly estimated by assuming inhalation rate of $1.5 \mathrm{~m}^{3} \mathrm{~h}^{-1}$ for moderate activities and $8 \mathrm{~h}$ working shift (Jackson et al., 2012). The inhalation dose was calculated by the following equation:

ID $=C_{\text {air }}^{*} I_{\text {rate }}^{*} T_{w}^{*} f_{r} / B W$

where ID is inhalation dose for workers in the workplace in $\mu \mathrm{gg}^{-1}$ bw d ${ }^{-1} ; C_{\text {air }}$ is air concentration expressed in $\mu \mathrm{g} \mathrm{m}^{-3} ; \mathrm{I}_{\text {rate }}$ is the inhalation rate of a worker in $\mathrm{m}^{3} \mathrm{~h}^{-1} ; \mathrm{T}_{\mathrm{w}}$ is the exposure time

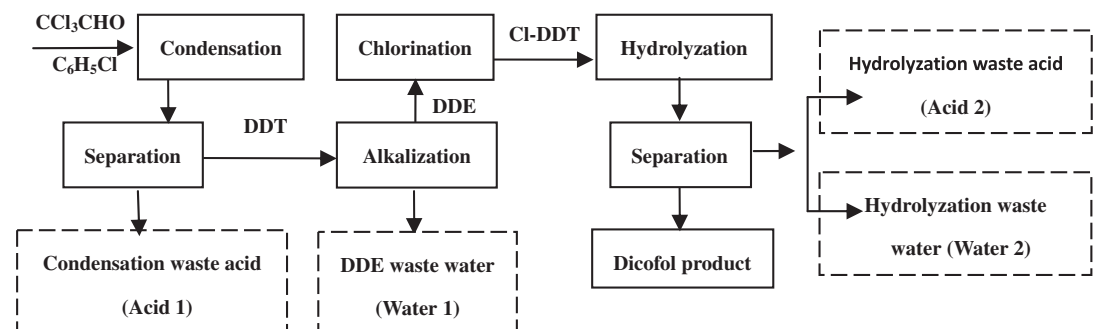

Fig. 1. The dicofol production process. 
Table 1

Workshop air, waste acid, waste water, and dicofol sample information.

\begin{tabular}{|c|c|c|c|}
\hline Item & Sampling position & Size of sample & Annual output \\
\hline Air 1 & Outside the condensation kettle, on the 5 th floor & $0.06 \mathrm{~m}^{3}$ & $\mathrm{na}^{\mathrm{a}}$ \\
\hline Air 2 & Outside the alkalization kettle, on the 4 th floor & $0.06 \mathrm{~m}^{3}$ & na \\
\hline Air 3 & Outside the chlorination kettle, on the 3rd floor & $0.06 \mathrm{~m}^{3}$ & na \\
\hline Air 4 & Inside the workers' rec room, on the 3rd floor & $0.06 \mathrm{~m}^{3}$ & na \\
\hline Air 5 & Outside the hydrolyzation kettle, on the 2 nd floor & $0.06 \mathrm{~m}^{3}$ & na \\
\hline Air 6 & Next to the exit of the Acid 2 and the Water 2 areas, on the 1 st floor & $0.06 \mathrm{~m}^{3}$ & na \\
\hline Air 7 & Inside the dicofol product packaging workshop & $0.06 \mathrm{~m}^{3}$ & na \\
\hline Acid 1 & Condensation acid (sulfuric acid) from the condensation kettle & $4 \mathrm{~kg}$ & $840 \mathrm{t}$ \\
\hline Acid 2 & Hydrolyzation acid (sulfonic acid) from the hydrolyzation kettle & $4 \mathrm{~kg}$ & $100 \mathrm{t}$ \\
\hline Water 1 & DDE-process waste water from the alkalization kettle & $20 \mathrm{~kg}$ & $1440 \mathrm{t}$ \\
\hline Water 2 & Hydrolyzation waste water from the hydrolyzation kettle & $20 \mathrm{~kg}$ & $2000 \mathrm{t}$ \\
\hline Dicofol & Dicofol product from the packaging workshop & $10 \mathrm{~g}$ & $2000 \mathrm{t}$ \\
\hline
\end{tabular}

a na: not applicable.

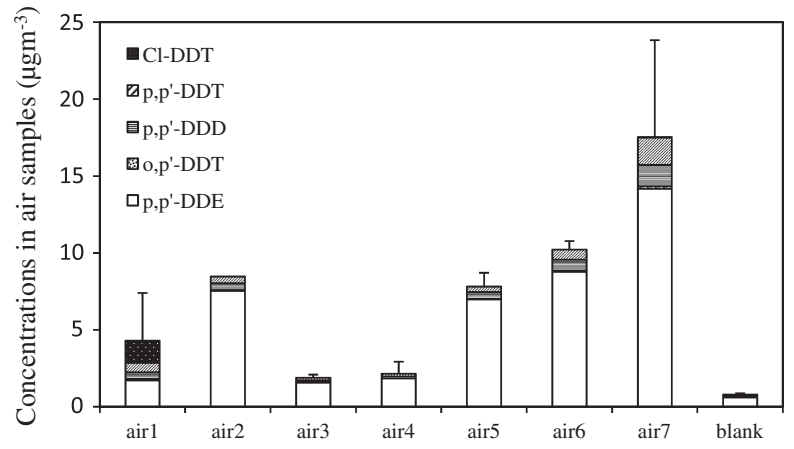

Fig. 2. $\Sigma D D T$ concentrations in the workshop air samples.

in the workplace $(h) ; f_{r}$ is inhalation absorption factor and 1 was used assuming 100\% absorption (Jackson et al., 2012); and BW is body weight of workers $(60 \mathrm{~kg})$.

The total estimated daily intakes of $\Sigma$ DDTs for workers by inhalation in the workplace were in the range of $0.38-3.51 \mu \mathrm{g} \mathrm{kg}^{-1}$ bw d $d^{-1}$ for moderate activities. By comparison with the recommended tolerable daily intake (TDI) of USA EPA, which is $0.5 \mu \mathrm{g} \mathrm{kg}^{-1}$ bw d ${ }^{-1}$ (oral intake) (Non-Carcinogen Tolerable Daily Intake (TDI) Values from USA EPA), the daily intakes by inhalation for workers in the workplace in this study were already comparable with or even much more higher than the TDI, especially in the packing workplace $\left(3.51 \mu \mathrm{g} \mathrm{kg}^{-1} \mathrm{bw} \mathrm{d}^{-1}\right)$. DDTs is known to be absorbed by humans in direct proportion to dietary exposure; halflife $\left(t_{1 / 2}\right)$ for clearance is $10-20$ years. Thus, it is indicated that the risk of occupational exposure to $\Sigma$ DDTs by inhalation in the workplace of the dicofol plant investigated was considerably high.

Except air samples, waste acid, waste water, and dicofol product are also main sources of $\Sigma$ DDTs that are discharged into the environment and the $\Sigma$ DDTs concentrations in these media are presented in Table 2. o, $\mathrm{p}^{\prime}$-DDT and $\mathrm{p}, \mathrm{p}^{\prime}$-DDT are the two main isomers formed from $\mathrm{CCl} 3 \mathrm{CHO}$ and $\mathrm{C} 6 \mathrm{H} 5 \mathrm{Cl}$. p, $\mathrm{p}^{\prime}$-DDT can be transformed into $\mathrm{p}, \mathrm{p}^{\prime}$-dicofol, whereas $\mathrm{o}, \mathrm{p}^{\prime}$-DDT is not readily chlorinated, so the p, $\mathrm{p}^{\prime}$-DDT fraction decrease more rapidly than the $\mathrm{o}, \mathrm{p}^{\prime}$-DDT fraction during the dicofol production process. Sample "Acid 1" was collected from the condensation kettle, and this would have been used (and recycled several times) as a reagent in the hydrolyzation kettle. The concentrations of $\Sigma$ DDTs in sample "Acid 2", taken from the hydrolyzation kettle, were much higher than those in sample "Acid 1". p,p'-DDE, p,p'-DDT and o,p'-DDT were the main congeners found in "Acid 2". Sample "Water 1" was from the alkalization kettle, where p,p'-DDT is converted into p,p'-DDE, and a high p,p'-DDE concentration (375 $\mu \mathrm{g} \mathrm{kg-1)}$ was found in this sample. Sample "Water 2" was collected from the hydrolyzation kettle, and contained similar components to the sample "Acid 2".

The highest $\Sigma$ DDTs concentration in the waste water samples was $456 \mu \mathrm{g} \mathrm{kg}^{-1}$. The $\Sigma$ DDTs concentrations in the dicofol product was $4.74 \mathrm{~g} \mathrm{~kg}^{-1}$, and the $p, p^{\prime}$-DDT concentrations were $0.59 \mathrm{~g} \mathrm{~kg}^{-1}$, meeting Chinese standards $\left(p, p^{\prime}\right.$-DDT $\leqslant 1 \mathrm{~g} \mathrm{~kg}^{-1}$ in dicofol product). Therefore, on the basis of the annual dicofol production $\left(2000 \mathrm{t} \mathrm{a}^{-1}\right)$ in this company, the annual amount of $\Sigma$ DDTs and $p, p^{\prime}$-DDT directly released to the environment will be $9480 \mathrm{~kg}$ and $1080 \mathrm{~kg}$, respectively.

\section{2. $P C D D / F$ emissions and characterization}

The PCDD/F concentrations found in the waste acid, waste water, and dicofol samples are shown in Table 3. The international toxicity equivalency factor (I-TEF) values were used to calculate the toxic equivalents (I-TEQs) for the PCDD/Fs.

The total 2,3,7,8-PCDD/F ( $\Sigma 2,3,7,8-\mathrm{PCDD} / \mathrm{Fs})$ concentration was 16 times higher in "Water 2" than in "Water 1", and the I-TEQ was 48 times higher in "Water 2" than in "Water 1". The $\Sigma 2,3,7,8$ $\mathrm{PCDD} / \mathrm{F}$ concentration was 13 times higher in "Acid 2" than in "Acid 1", and the I-TEQ was 3 times higher in "Acid 2" than in "Acid 1 ". The PCDD/F concentrations were clearly higher after the chlorination process than before, indicating that PCDD/Fs were formed in the chlorination process. PCDD/Fs were also detected in the dicofol product, which had an I-TEQ of up to $86.3 \mathrm{ng}$ I-TEQ $\mathrm{kg}^{-1}$. Based on the annual outputs of the waste water, waste acid and dicofol listed in Table 1, the preliminary emission factors of PCDD/Fs for

Table 2

The concentrations of $\Sigma$ DDTs in the waste acid, waste water, and dicofol samples.

\begin{tabular}{|c|c|c|c|c|c|}
\hline DDT & Acid $1\left(\mu \mathrm{g} \mathrm{kg}^{-1}\right)$ & Acid $2\left(\mu \mathrm{g} \mathrm{kg}^{-1}\right)$ & Water $1\left(\mu \mathrm{g} \mathrm{kg}^{-1}\right)$ & Water $2\left(\mu \mathrm{g} \mathrm{kg}^{-1}\right)$ & Dicofol $\left(\mathrm{g} \mathrm{kg}^{-1}\right)$ \\
\hline$p, p^{\prime}-\mathrm{DDE}$ & 2.74 & 59.8 & 375 & 19.7 & 3.91 \\
\hline$p, p^{\prime}-\mathrm{DDD}$ & 0.94 & 16.4 & 3.17 & 3.19 & 0.01 \\
\hline$o, p^{\prime}-\mathrm{DDT}$ & 0.01 & 110 & 34.8 & 2.16 & 0.16 \\
\hline$p, p^{\prime}-\mathrm{DDT}$ & 0.33 & 147 & 43.5 & 1.41 & 0.59 \\
\hline Cl-DDT & 0.82 & 1.72 & 0.47 & 49.2 & 0.06 \\
\hline$\Sigma$ DDTs & 4.85 & 335 & 456 & 75.6 & 4.74 \\
\hline
\end{tabular}


Table 3

PCDD/F concentrations in the samples.

\begin{tabular}{|c|c|c|c|c|c|}
\hline Congener & Acid $1\left(\mathrm{pg} \mathrm{kg}^{-1}\right)$ & Acid $2\left(\mathrm{pg} \mathrm{kg}^{-1}\right)$ & Water $1\left(\mathrm{pg} \mathrm{kg}^{-1}\right)$ & Water $2\left(\mathrm{pg} \mathrm{kg}^{-1}\right)$ & Dicofol $\left(\mathrm{ng} \mathrm{kg}^{-1}\right)$ \\
\hline $2,3,7,8-\mathrm{TCDF}$ & 0.1 & 0.05 & $\mathrm{ND}^{\mathrm{a}}$ & 0.01 & 0.1 \\
\hline $1,2,3,7,8-\mathrm{PeCDF}$ & 136 & 68.1 & 0.68 & 0.46 & ND \\
\hline $2,3,4,7,8-\mathrm{PeCDF}$ & 0.35 & 0.17 & 0.67 & 24 & ND \\
\hline $1,2,3,4,7,8-\mathrm{HxCDF}$ & 189 & 35.3 & 1.1 & 218 & 16.9 \\
\hline $1,2,3,6,7,8-\mathrm{HxCDF}$ & 10.5 & 1.8 & 0.28 & 21.3 & 0.1 \\
\hline $2,3,4,6,7,8-\mathrm{HxCDF}$ & 12.5 & 1.3 & 0.66 & 131 & 27 \\
\hline $1,2,3,7,8,9-\mathrm{HxCDF}$ & 42.9 & 21.5 & 1.31 & 0.8 & 3.1 \\
\hline $1,2,3,4,6,7,8-\mathrm{HpCDF}$ & 18.8 & 256 & 0.51 & 158 & 93 \\
\hline $1,2,3,4,7,8,9-\mathrm{HpCDF}$ & 21.3 & 10.7 & 0.8 & 1.1 & 6.1 \\
\hline OCDF & 42.4 & 187 & 6.3 & 87.2 & 33.1 \\
\hline $2,3,7,8-\mathrm{TCDD}$ & 5.8 & 38.3 & 0.3 & 1.02 & 71.4 \\
\hline $1,2,3,7,8-\mathrm{PeCDD}$ & 0.47 & 0.23 & 0.62 & 31.3 & 3.9 \\
\hline $1,2,3,4,7,8-\mathrm{HxCDD}$ & 2.4 & 144 & 0.32 & 0.8 & 22 \\
\hline $1,2,3,6,7,8-\mathrm{HxCDD}$ & 1.6 & 379 & 0.32 & 22.8 & 38 \\
\hline $1,2,3,7,8,9-\mathrm{HxCDD}$ & 1.1 & 105 & 0.6 & 18.3 & 3.2 \\
\hline $1,2,3,4,6,7,8-\mathrm{HpCDD}$ & 5.3 & 390 & 0.69 & 148 & 78.6 \\
\hline OCDD & 25.4 & 5066 & 48.2 & 161 & 75.5 \\
\hline$\Sigma 2,3,7,8-\mathrm{PCDD} / \mathrm{Fs}$ & 516 & 6703 & 63 & 1024 & 472 \\
\hline I-TEQ & 39.6 & 122 & 1.5 & 73.3 & 86.3 \\
\hline
\end{tabular}

${ }^{a}$ ND: Below the limit of detection.

the waste water, waste acid and dicofol in the dicofol production were calculated as $0.074 \mu \mathrm{g}$ I-TEQ $\mathrm{t}^{-1}, 0.023 \mu \mathrm{g}$ I-TEQ $\mathrm{t}^{-1}$ and $86.3 \mu \mathrm{g}$ I-TEQ $\mathrm{t}^{-1}$, respectively. Therefore, using the annual dicofol production by this company, the annual amount of PCDD/Fs released to the environment could be the equivalent of up to $0.17 \mathrm{~g}$ I-TEQ. In addition, the concentrations of PCDD/Fs in dicofol were compared with other chlorine-containing organic compounds (Holt et al., 2012). The PCDD/F concentrations in dicofol are clearly lower than those in chloranil (Liu et al., 2012), but are equivalent to or a little higher than those in $p$-dichlorobenzene, 2,4-D and triclosan (Ni et al., 2005; Liu et al., 2013).

There have been studies in places where dicofol has been used as an agricultural acaricide. It was found that $\Sigma 2,3,7,8-\mathrm{PCDD} / \mathrm{F}$ concentrations of $0.017-5.04 \mathrm{ng} \mathrm{kg}^{-1} \mathrm{dw}$ (dry weight) in a typical area in eastern China where dicofol has been widely used for pest control (Liu and Liu, 2009). It is found that some of the sediments from that area had similar PCDD/F homologue patterns to the dicofol product we analyzed in this study. Dicofol use could, therefore, be an important source of PCDD/F pollution.

The PCDD/F homologue profiles are often indicative of specific formation pathways. As is shown in Fig. 3, PCDDs were dominant in the samples from the dicofol plant, especially the "Acid 2" and "Water 1" samples, in which OCDD was present at higher concentrations than the other congeners. The degree of chlorination of the PCDD/Fs found in the samples ranged between 5.48 and 7.19. It was found that the degree of chlorination of the PCDD/Fs was higher in the later samples than in the earlier samples because of an excess of $\mathrm{Cl}_{2}$ being added during the chlorination of DDE to give

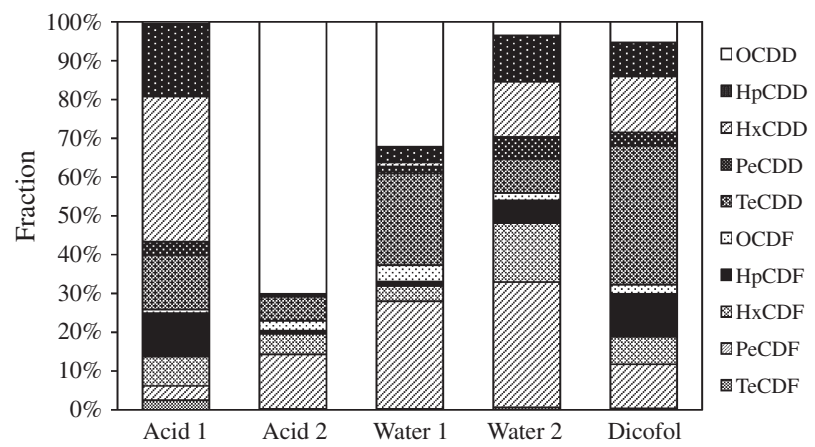

Fig. 3. $P C D D / F$ homologue patterns in the samples.
Cl-DDT, which would allow more high-chlorinated PCDD/F congeners to be generated.

Using our results and previously published work (Babushok and Tsang, 2003; Evans and Dellinger, 2005), we propose a pathway for the formation of PCDD/Fs during dicofol production. $\mathrm{C}_{6} \mathrm{H}_{5} \mathrm{Cl}$ and $\mathrm{Cl}_{2}$ are used as raw materials, so the $\mathrm{C}_{6} \mathrm{H}_{5} \mathrm{Cl}$ that had not already reacted with $\mathrm{CCl}_{3} \mathrm{CHO}$ could react with $\mathrm{Cl}_{2}$ to produce polychlorobenzenes (Liu et al., 2004). In a similar way to the formation of PCDD/Fs during p-dichlorobenzene production, chlorinated PCDD/Fs will be formed from the polychlorobenzenes during the dicofol production process.

\section{Conclusions}

Our results show that DDT compounds are the primary contaminants in the dicofol production process. The $\mathrm{EDDT}$ concentrations in workshop air samples were at $1.88-17.53 \mu \mathrm{g} \mathrm{m}^{-3}$. The total estimated daily intakes of $\Sigma$ DDTs for workers by inhalation in the workplace were in the range of $0.38-3.51 \mu \mathrm{g} \mathrm{kg}^{-1} \mathrm{bw} \mathrm{d}^{-1}$ for moderate activities. Large amount of $\Sigma$ DDTs were directly released to the environment via the use of dicofol, the annual amount of $\Sigma$ DDTs and $p, p^{\prime}$-DDT released were $9480 \mathrm{~kg}$ and $1080 \mathrm{~kg}$, respectively. It will be necessary to monitor DDT concentrations in the dicofol product, waste acids, and waste water regularly to prevent DDT emissions exceeding the standard because of improper production practices. The preliminary emission factors of PCDD/Fs for the waste water, waste acid and dicofol product in the dicofol production were calculated as $0.074 \mu \mathrm{g}$ I-TEQ $\mathrm{t}^{-1}, 0.023 \mu \mathrm{g}$ I-TEQ $\mathrm{t}^{-1}$ and $86.3 \mu \mathrm{g} \mathrm{I-TEQ} \mathrm{t}^{-1}$, respectively. The annual amount of PCDD/Fs released to the environment was $0.17 \mathrm{~g}$ I-TEQ. Therefore, it was concluded that PCDD/F emissions from the production of dicofol could not be ignored.

\section{Acknowledgements}

This study was supported by the National 973 Program (2011CB201500), the Environmental Public Welfare Projects (201209019), the National 863 Program (2012AA062803), and the National Natural Science Foundation of China (21077121).

\section{References}

Babushok, V.I., Tsang, W., 2003. Gas-phase mechanism for dioxin formation. Chemosphere 51, 1023-1029. 
Chen, D., Zhang, X., Mai, B., Sun, Q., Song, J., Luo, X., Zeng, E.Y., Hale, R.C., 2009. Polychlorinated biphenyls and organochlorine pesticides in various bird species from northern China. Environ. Pollut. 157, 2023-2029.

de la Cal, A., Eljarrat, E., Raldúa, D., Durán, C., Barceló, D., 2008. Spatial variation of DDT and its metabolites in fish and sediment from Cinca River, a tributary of Ebro River (Spain). Chemosphere 70, 1182-1189.

Evans, C.S., Dellinger, B., 2005. Mechanisms of dioxin formation from the hightemperature oxidation of 2-chlorophenol. Environ. Sci. Technol. 39, $122-$ 127.

Holt, E., Weber, R., Stevenson, G., Gaus, C., 2012. Formation of dioxins during exposure of pesticide formulations to sunlight. Chemosphere 88, 364-370.

Hui, L.L., Hedley, A.J., Kypke, K., Cowling, B.J., Nelson, E.A.S., Wong, T.W., van Leeuwen, F.X.R., Malisch, R., 2008. DDT levels in human milk in Hong Kong, 2001-02. Chemosphere 73, 50-55.

Jackson, K., Aries, E., Fisher, R., Anderson, D.R., Parris, A., 2012. Assessment of exposure to $\mathrm{PCDD} / \mathrm{F}, \mathrm{PCB}$, and $\mathrm{PAH}$ at a basic oxygen steelmaking (BOS) and an iron ore sintering plant in the UK. Ann. Occup. Hyg. 56, 37-48.

Li, J., Zhang, G., Qi, S., Li, X., Peng, X., 2006. Concentrations, enantiomeric compositions, and sources of $\mathrm{HCH}$, DDT and chlordane in soils from the Pearl River Delta. South China Sci. Total Environ. 372, 215-224.

Liu, J., Liu, W., 2009. Distribution of polychlorinated dibenzo-p-dioxins and dibenzofurans (PCDDs/Fs) and dioxin-like polychlorinated biphenyls (dioxinlike PCBs) in the soil in a typical area of eastern China. J. Hazard. Mater. 163, 959-966.
Liu, W., Zheng, M., Wang, D., Xing, Y., Zhao, X., Ma, X., Qian, Y., 2004. Formation of $\mathrm{PCDD} / \mathrm{Fs}$ and $\mathrm{PCBs}$ in the process of production of 1,4-dichlorobenzene. Chemosphere 57, 1317-1323.

Liu, W., Tao, F., Zhang, W., Li, S., Zheng, M., 2012. Contamination and emission factors of $\mathrm{PCDD} / \mathrm{Fs}$, unintentional $\mathrm{PCBs}, \mathrm{HxCBz}, \mathrm{PeCBz}$ and polychlorophenols in chloranil in China. Chemosphere 86, 248-251.

Liu, W., Li, H., Tao, F., Li, S., Tian, Z., Xie, H., 2013. Formation and contamination of PCDD/Fs, PCBs, PeCBz, HxCBz and polychlorophenols in the production of 2,4-D products. Chemosphere 92, 304-308.

Ni, Y., Zhang, Z., Zhang, Q., Chen, J., Wu, Y., Liang, X., 2005. Distribution patterns of PCDD/Fs in chlorinated chemicals. Chemosphere 60, 779-784.

Qiu, X., Zhu, T., Yao, B., Hu, J., Hu, S., 2005. Contribution of dicofol to the current DDT pollution in China. Environ. Sci. Technol. 39, 4385-4390.

UNEP, 2005. Standardized Toolkit for Identification and Quantification of Dioxin and Furan Release, second ed. UNEP Chemicals, Geneva.

Yang, X., Wang, S., Bian, Y., Chen, F., Yu, G., Gu, C., Jiang, X., 2008. Dicofol application resulted in high DDTs residue in cotton fields from northern Jiangsu province. China J. Hazard. Mater. 150, 92-98.

Zhang G, Parker, A. House, A, Mai, B, Li, X, Kang, Y, Wang Z, 2002. Sedimentary Records of DDT and $\mathrm{HCH}$ in the Pearl River Delta, South China. Environ. Sci. Technol. 36, 3671-3677.

Zheng, G.J., Leung, A.O., Jiao, L.P., Wong, M.H., 2008. Polychlorinated dibenzo-pdioxins and dibenzofurans pollution in China: sources, environmental levels and potential human health impacts. Environ. Int. 34, 1050-1061. 